\title{
Notes on taxonomy of Lispe Latreille (Diptera: Muscidae)
}

\section{К таксономии Lispe Latreille (Diptera: Muscidae)}

\author{
N.E. Vikhrev \\ H.E. Buxpeв
}

\begin{abstract}
Zoological Museum, Lomonosov Moscow State University, Bolshaya Nikitskaya 6, Moscow 125009, Russia. E-mail: nikita6510@ya.ru Зоологический музей, Московский государственный университет им. М.В. Ломоносова, Большая Никитская ул., 6, Москва 125009 , Россия.
\end{abstract}

KEY WORDS: Lispe emdeni, Lispe scalaris, Lispe angustipalpis, Muscidae, Diptera, new species, new synonym.

КЛЮЧЕВЫЕ СЛОВА: Lispe emdeni, Lispe scalaris, Lispe angustipalpis, Muscidae, Diptera, новый вид, новый синоним.

ABSTRACT. Lispe emdeni sp.n. is described from Western India. Two new synonyms are proposed: for Lispe angustipalpis Stein, 1920 (= Lispe fuscipalpis Malloch, 1929 syn.n.) and for Lispe scalaris Loew, 1847 (=Lispe persica Becker, 1904 syn.n.). A short review of several other Lispe species related to the above mentioned ones is given. A correction to the designation in previous article [Vikhrev, 2011a] is added.

РЕЗЮМЕ. Lispe emdeni sp.n. описан из западной Индии. Установлено 2 новых синонима: для Lispe angustipalpis Stein, 1920 (=Lispe fuscipalpis Malloch, 1929 syn.n.) и для Lispe scalaris Loew, 1847 (=Lispe persica Becker, 1904 syn.n.). Дан краткий обзор других видов Lispe, родственных трем вышеупомянутым. Также добавлена коррекция ошибки, допущенной в предыдущей статье [Vikhrev, 2011a].

\section{Introduction}

Hennig's [1960] monograph is still the best source on the taxonomy of Lispe Latreille, 1796. Apart from everything else, Hennig offered a subdivision of this large genus onto 6 species-groups and several species with uncertain relation. His subdivision mostly seems well-founded, partly not enough so, but anyway this is better than two hundreds of species without any order. Recently I proposed to add one more Lispe leucospila species-group for two Palaearctic-Oriental species and several Afrotropical ones of uncertain taxonomic status [Vikhrev, 2011b]. The present taxonomic notes deal with several Lispe species which probably are not closely related to each other. L. persica Becker, 1904 belongs to Hennig's small Lispe scalaris species-group which becomes even smaller after the here proposed treatment of $L$. persica as a new synonym of $L$. scalaris
Loew, 1847. For the here considered L. angustipalpis Stein, 1920 and two related species I propose a new Lispe pumila species-group (named so after the oldest species included). For the here described L. emdeni sp.n. I can only suppose the relation to another "groupless" species L. nana Macquart, 1835.

\section{Material and methods}

The majority of the specimens studied are in the Zoological Museum of Moscow University (ZMUM) (in this case not indicated in the text).

Geographical coordinates are given in the Decimal Degrees format.

The following abbreviations for morphological structures are used: $f 1, t 1, f 2, t 2, f 3, t 3$ - fore-, mid-, hind- femur or tibia; $a c$ - acrostichal setae; $d c$ dorsocentral setae; $a, p, d, v$ - anterior, posterior, dorsal, ventral seta(e); prst — presutural, post — postsutural.

The abbreviation for the tarsi as tar followed by a pair of digits separated by a hyphen was proposed by Vikhrev [2011a]: the first digit (1 to 3) gives the leg number and the second digit ( 1 to 5 ) the number of the tarsal segment. For example, tar 1-4 - 4-th segment of fore tarsus; tar3-1 — hind basitarsus.

\section{Taxonomic part \\ Lispe emdeni Vikhrev sp.n.}

Figs 1-5.

MATERIAL. Holotype $\sigma^{r}$, India, Rajasthan state, Jaipur env. (26.96 $\left.{ }^{\circ} \mathrm{N} 75.85^{\circ} \mathrm{E}\right), 21-22 . I I I .2011, \mathrm{~N}$. Vikhrev.

Paratypes: $8 \sigma^{7} \sigma^{7}, 3$ 우 with the same label as holotype; 7 $\sigma^{\top} \sigma^{\top}, 6$ O 6 , India, Rajasthan state, Sawai Madhopur env. $\left(26.02^{\circ} \mathrm{N}\right.$ $\left.76.38^{\circ} \mathrm{E}\right), 26 . I I .2011$, N.Vikhrev (ZMUM); $3 \sigma^{7} \sigma^{7}$, Madhya Pradesh 

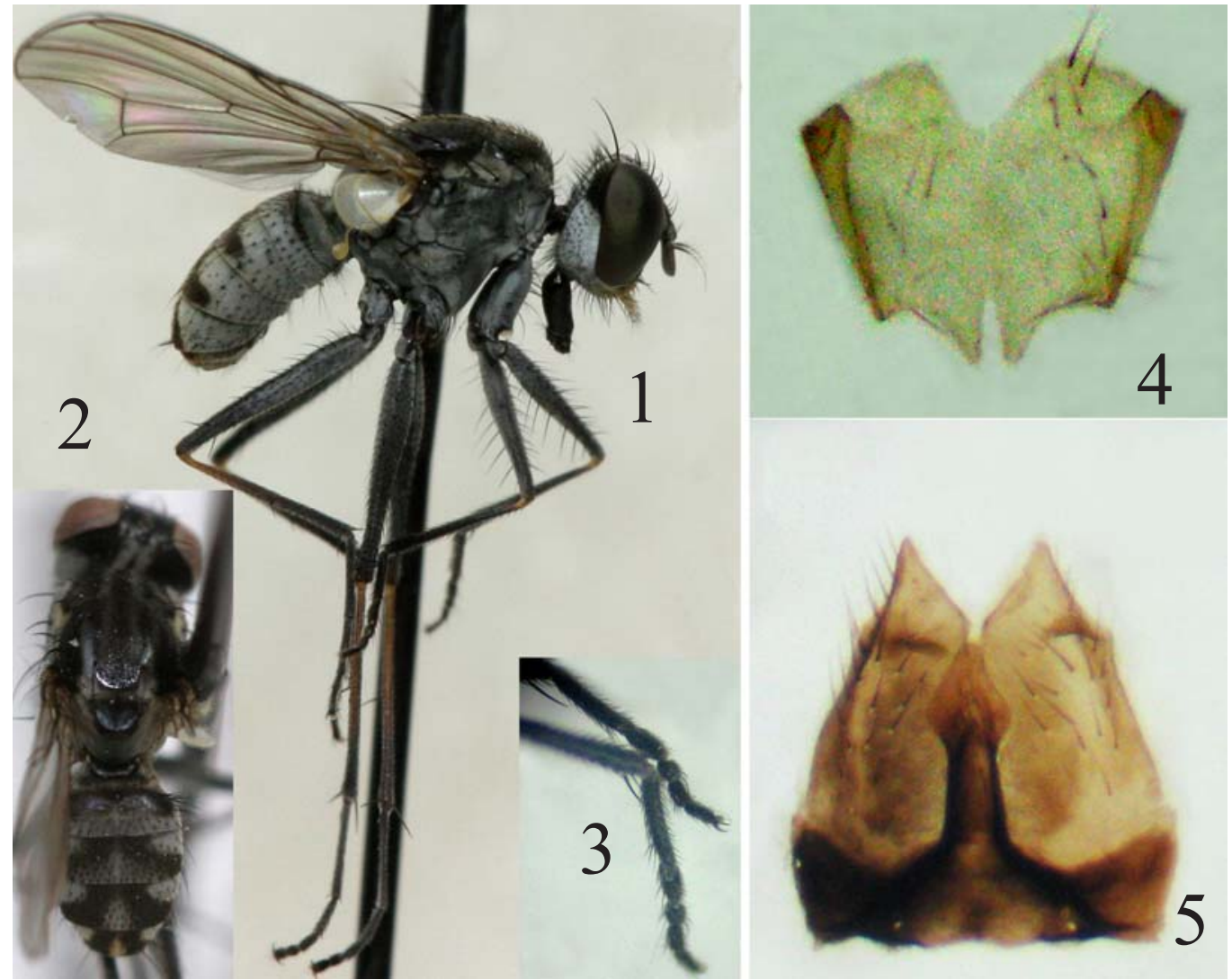

Figs 1-5. Lispe emdeni Vikhrev sp.n., $0^{\text {? }}: 1$ - lateral view; 2 - dorsal view; 3 - fore tarsi; 4 - öåđề; 5 - sternite 5.

Рис. 1-5. Lispe emdeni Vikhrev sp.n., о’: 1 - вид сбоку; 2 - вид сверху; 3 - передние лапки; 4 - церки; 5 - 5-й стернит.

state, Jubblepore (= Jabalpur, H”23.2N 79.9E), 03.V.1905, E. Brunetti (Natural History Museum, London (BMNH)*.

DESCRIPTION. Male (Figs. 1, 2). Body size 4-4.5 mm.

Head. Frontal triangle narrow, black, slightly shining; interfrontalia math black; fronto-orbital plates mostly black, slightly shining, but its anterior margin dusted as parafascial; face and parafacials densely dirty-yellow dusted. Occiput grey with a pair of black shining spots in upper $1 / 3$. Fronto-orbital plates with 4 inclinate setae and an outer row of 5-6 proclinate setulae in posterior half. Antenna black, arista long plumose. Vibrissae weak, palpi wide, yellow.

Thorax. Pleura, humeral calli and notopleuron densely grey dusted. Disc of the scutum and scutellum subshinig black, scutum with a pair of thinly dusted grey vittae mesad to dorsocentral rows and a pair of small dusted spots at posterior margin. $2(1)+4 d c$, only the last one (6th) strong, 2nd and 5th - moderately strong; prst ac hairs in 3-4 rows. Meron with 1-4 setulae above hind coxa. Wing hyaline, cell $\mathrm{R}_{4+5}$ not narrowed at apex.

Legs black, densely grey dusted, only knees and basal half of posterior tibiae yellowish. $t 1$ without seta.

*I had not personally examined specimens from BMNH, but a draft description of a new species was found in Emden's handwritten unpublished notes. Emden's detailed description leaves no doubts that my series from Rajasthan and Brunetti's specimens from neighbouring state Madhya Pradesh are conspecific.
Fore tarsus modified: $\operatorname{tar} 1-1$ to tar $1-4$ shortened and somewhat compressed, $\operatorname{tar} 1-1$ on $p$ surface with a flat apical process reaching the middle of $\operatorname{tar} 1-2$ (Fig. 3). $f 2$ without strong setae except 1 apical $p d$. $t 2$ with submedian $p$ seta. Hind coxa without seta on inner posterior surface. $f 3$ without $a v$ setae and with $1 p v$ at apex. $t 3$ with 1 ad and $1 p d$ setae.

Abdomen grey dusted with blackish trapezoid spots on tergites 3 to 5 , pattern on tergite 3 rather vague. Grey median vitta interrupted at anterior margins of tergites and widened at posterior margins. Cercal plate with weak sclerotization (Fig. 4), sternite 5 with medial arrow-shaped process (Fig. 5).

Female differs from male as follows: body size 4-5 $\mathrm{mm}$; fore tarsus unmodified; dusting of scutum more developed; abdominal spots vaguer.

DIAGNOSIS. Lispe emdeni sp.n. in my opinion is related to Lispe nana Macquart. The two species share the general habitus and general dusting pattern, leg chaetotaxy, structure of male aedeagus. These species may be easily separated as follows:

— $d c 2+3$ all strong. prst ac hairs in 2 rows. Meron bare above hind coxa. Disc of scutum mostly brownish dusted. Abdomen whitish dusted, with larger and clearly limited black spots. $\sigma^{7}$ fore tarsus unmodified nana Macquart $-2(1)+4 d c$, only the last one (6-th) strong, 2-nd and 5-th - moderately strong. prst ac hairs in 3-4 rows. Meron 
with 1-4 setulae above hind coxa. Disc of scutum mostly subshining. Abdomen grey dusted, with smaller and more vague black spots. $\bigcirc^{7}$ fore tarsus modified emdeni sp.n.

ETYMOLOGY. The new species is named in honour of Dr. F. van Emden.

\section{Lispe pumila species-group}

I propose to include 3 species in a new Lispe pumila species-group (named so after the oldest species included) that is: closely related to each other L. angustipalpis Stein, 1920 and L. pumila Wiedemann, 1824 and less obviously related Lispe pygmaea Fallén, 1825. These species share the following characters: palpi very narrow (for Lispe); katepisternal setae forming nearly equilateral triangle; sternite 5 with a pair of sclerites attached to its internal surface; similar habitats: the flies are found on grass vegetation near fresh water. L. pumila is common an Oriental region, L. angustipalpis is also Oriental species, but less common and seems to be restricted in its distribution to the equatorial zone, L. pygmaea is a widespread and common Palaearctic species.

\section{Lispe angustipalpis Stein, 1920 \\ Figs 6, 8.}

Lispe angustipalpis Stein, 1920: 60. Type locality: Java.

Lispe fuscipalpis Malloch, 1929: 155 — syn.n. Type locality: Vanuatu.

Lispe pumiloides Snyder, 1965: 265. Type locality: Micronesia, Pulau and Yap.

MATERIAL EXAMINED. $90^{7} \sigma^{7}, 7$ 우, Thailand: Phuket prov., $08.063^{\circ} \mathrm{N} 98.277^{\circ} \mathrm{E}, 18-26 . I \mathrm{II} .2009$, N.Vikhrev; 1 + , Phang Nga prov., Similan Isl. 4, 12.XII.2010, N. Vikhrev.

Lispe pumila Wiedemann, 1824

Fig. 7.

Lispe pumila Wiedemann, 1824: 51. Type locality: "India orient".

MATERIAL EXAMINED. 95 specimens from: Cambodia: Kampot, Kep and Koh Kong prov.; India: Goa state; Myanmar: Shan state; Thailand: Bangkok, Chanthaburi, Chonburi, Phang Nga, Phuket and Rayong prov.

\section{Lispe pygmaea Fallén, 1825} rod.

Lispe pygmaea Fallén, 1825: 94. Type locality: Sweden, Espe-

MATERIAL EXAMINED. 170 specimens from: Azerbaijan; Egypt: Luxor reg.; Georgia; India: Rajasthan state; Israel; Mongolia: Uvs prov.; Morocco: Essaouira prov.; Kazakhstan: Atyrau, East Kazakhstan, Kyzylorda and West Kazakhstan reg.; Russia: Altay, Amur, Buryatia, Dagestan, Krasnodar, Kursk, Moscow, Nizhny-Novgorod, Novosibirsk, Omsk, Primorsky, S-Peterburg, Tver, Ulyanovsk and Zabaikalsky reg.; Tajikistan: Dushanbe reg.; Turkey: Adana, Antalya Hatay, Kayseri, Konya, Mersin and Sakarya prov.; Turkmenistan: Dashoguz, Lebap and Mary prov.; Ukraine: Odessa reg.

DISCUSSION. According to Stein [1920], L. angustipalpis Stein was described from two females. The type material was reexamined by Pont [1970]. Pont has found that the specimen collected in Batavia (=Djakarta) and stored in Berlin (Museum für Naturkunde der Humboldt-Universität zu Berlin) is actually a male, this specimen was designated as the lectotype. The female specimen collected in Wonosobo and stored in Amsterdam (Zoölogisch Museum, Universiteit van Amsterdam, from 2011 this material is stored in Leiden (Nederlands Centrum Biodiversiteit (NCB Naturalis), de Universiteit Leiden) was designated as the paralectotype. Due to the kind help of Dutch colleagues Ben Brugge and Joke van Erkelens female paralectotype of L. angustipalpis was photographed (Fig. 6). This image and Stein's original description of L. angustipalpis leave no doubts that L. angustipalpis is conspecific to the specimens from Thailand in ZMUM, while the series from Thailand was compared with Malloch's type material of L. fuscipalpis by A.C. Pont and found conspecific (A.C. Pont, pers. comm.).

The detailed description of $L$. angustipalpis (as $L$. pumiloides) is given in Snyder [1965], but the published keys for Oriental Lispe do not mention L. angustipalpis (or L. fuscipalpis or L. pumiloides) and give somewhat erroneous information on L. pumila, so I offer below my own key for the species of the Lispe pumila species-group.

1. $2+3 d c$, all strong. $t 3$ without $a v$ seta. Meron bare above hind coxa. Abdominal tergites 3 to 5 with obscure spots in male, hardly distinct spots in female. Male fore coxa simple ................................................. pygmaea Fallén

$-2+4 d c 4$ anterior pairs very weak, hardly distinct. $t 3$ with $a v$ seta. Meron with 2-4 hairs above hind coxa. Abdominal tergites 3 to 5 with contrasting black spots in both sexes. Male fore coxa behind with a characteristic bunch of long wavy hairs ................................................... 2

2. Palpi black(ish). Spots on abdominal tergites 3 to 5 large and reaching posterior margin of tegites. Scutum blackish, only thinly dusted, with wider vittae angustipalpis Stein

- Palpi yellow. Spots on abdominal tergites 3 to 5 smaller and not reaching posterior margin of tegites. Scutum densely grey dusted, with narrow obscure vittae ..... pumila Wiedemann

\section{Lispe scalaris species-group}

Lispe scalaris species-group was proposed by Hennig [1960: 412] for Lispe scalaris Loew, Lispe persica Becker, Lispe nubilipennis Loew, 1873 and Lispe elegantissima Stackelberg, 1937. Hennig indicated the following group characters: $a c$ setulae in 2 rows distinctly separated from scutal setulae; lower katepisternal seta weak, hairlike; similar leg chaetotaxy ( $t 1$ without setae, t2 with $1 p, t 31$ ad seta only); similar abdominal pattern (though more or less developed in different species); similarity of male terminalia. It may be added that Lispe scalaris species-group includes the smallest Lispe species with body size about $4 \mathrm{~mm}$ and that the distribution of the group is restricted to the arid zone of the Palaearctic region. 


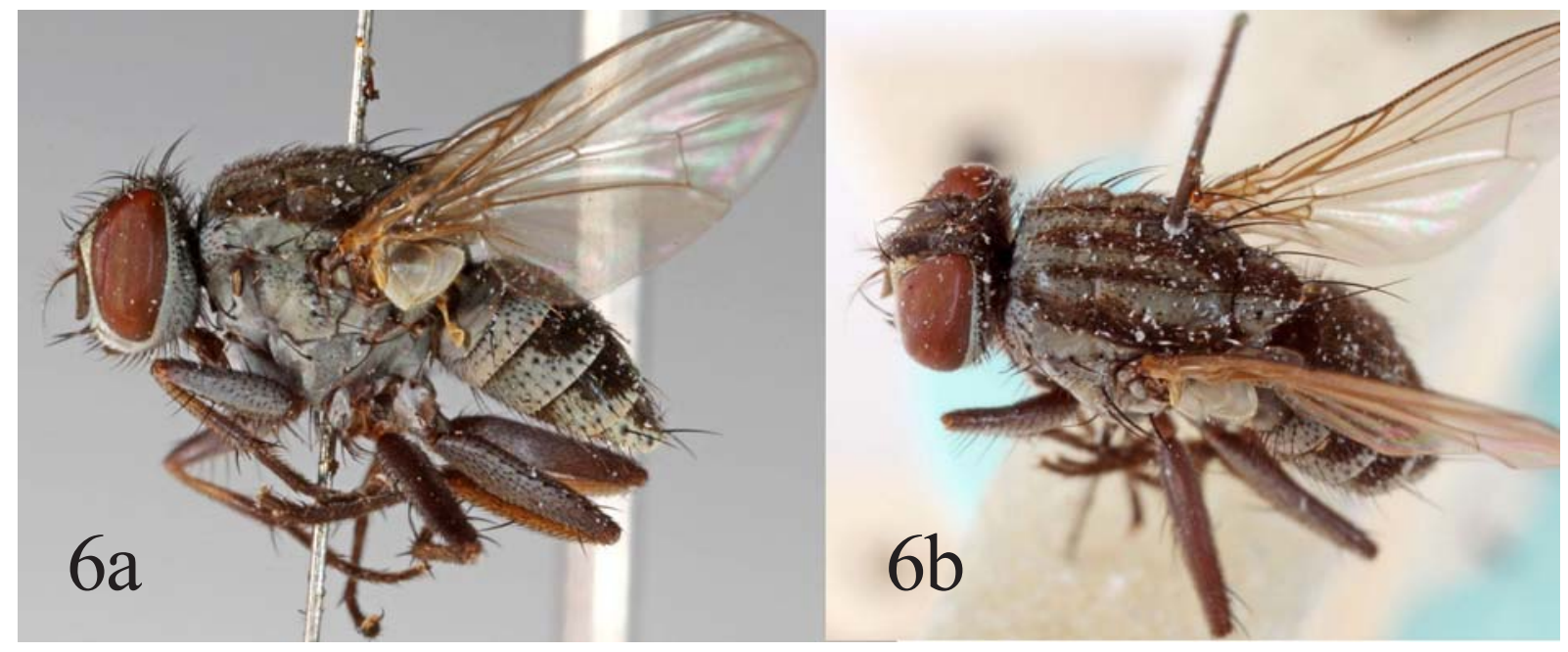

Figs 6. Lispe angustipalpis Stein, paralectotype ${ }^{\text {, }}$, lateral (a) and dorsal (b) view (photo by Joke van Erkelens). Рис. 6. Lispe angustipalpis Stein, паралектотип +, вид сбоку (а) и сверху (b) (фото Joke van Erkelens).

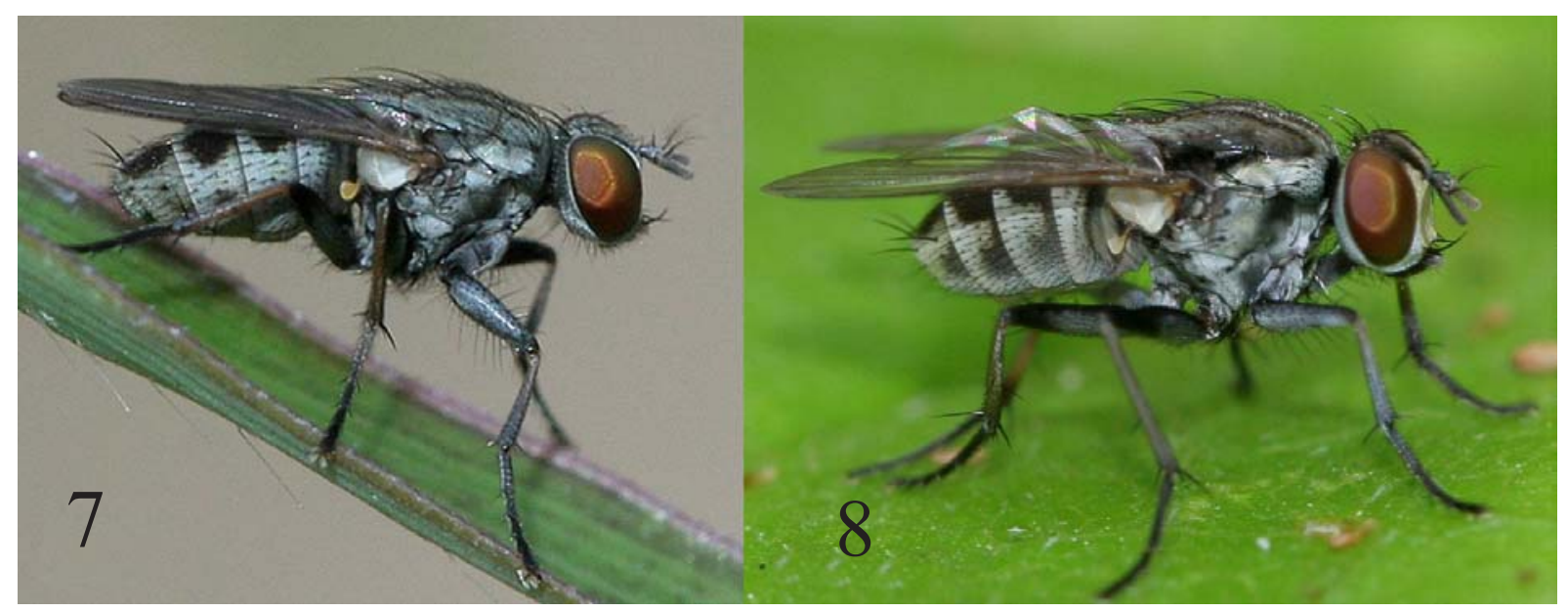

Figs 7-8. Lispe spp. ㅇ: 7 - L. pumila Wiedemann; 8 - L. angustipalpis Stein.

Рис. 7-8. Lispe spp. ㅇ: 7 - L. pumila Wiedemann; 8 - L. angustipalpis Stein.
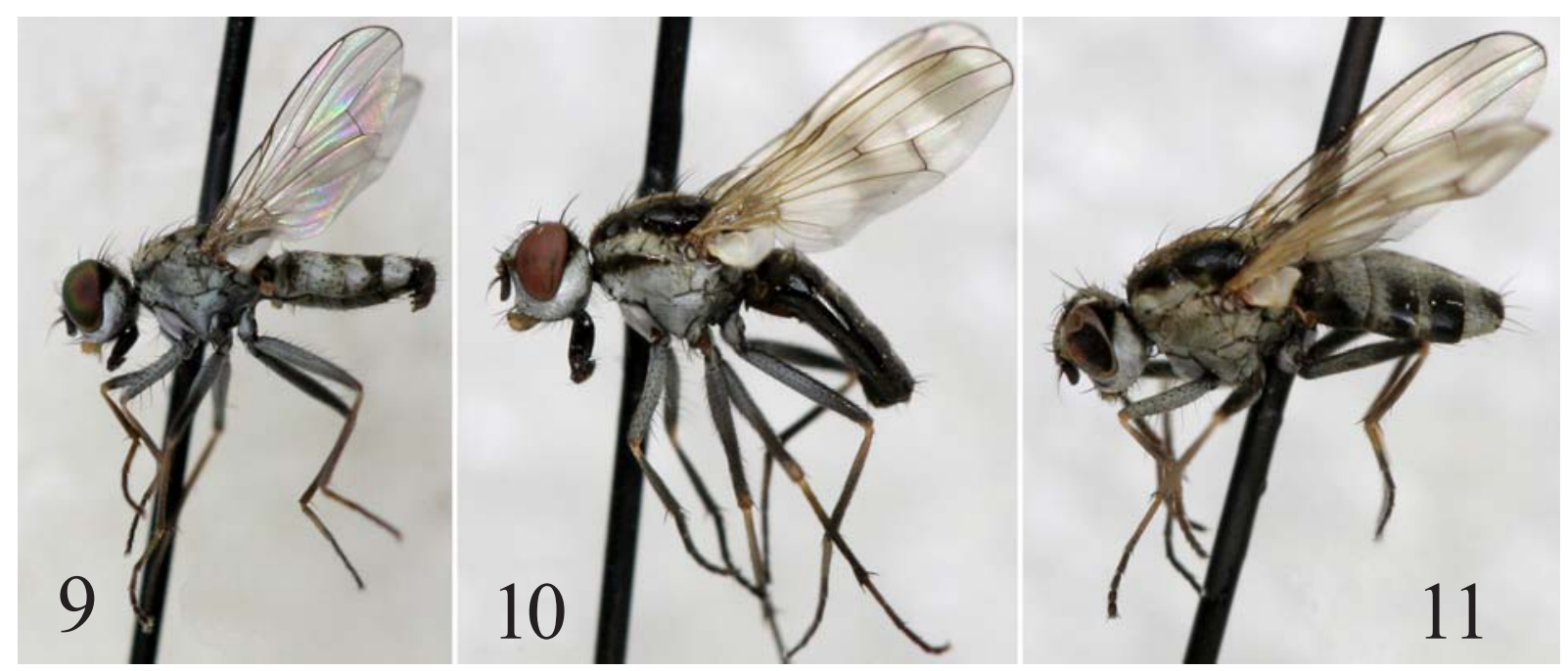

Figs 9-11. Lispe spp.: 9 - L. scalaris Loew, $0^{7} ; 10$ - Lispe elegantissima Stackelberg, + ; $11-$ L. nubilipennis Loew, ${ }^{+}$. Рис. 9-11. Lispe spp.: 9 - L. scalaris Loew, $0^{7} ; 10$ - Lispe elegantissima Stackelberg, + ; $11-$ L. nubilipennis Loew, + . 


\section{Lispe scalaris Loew, 1847}

Fig. 9. (Izmir)

Lispe scalaris Loew, 1847: 28. Type locality: Turkey, Smirna

Lispe persica Becker, 1904: 22 - syn.n. Type locality: S-E Iran, Sistan.

TYPE MATERIAL EXAMINED. $10^{7}, 2$ 우 syntypes of $L$. persica: Iran: Sistan (presently Sistan and Baluchestan Prov., $27^{\circ} \mathrm{N}$ $61^{\circ} \mathrm{E}$ ), 21.V.1898, N. Zarudnyi (Zoological Institute, St.-Petersburg (ZIN).

ADDITIONAL MATERIAL. $1 \sigma^{7}$, Egypt: Cairo, XI (Nov?); 2 $\mathrm{O}^{7} \mathrm{O}^{7}, 1$ 积 Assuan, II (Febr?) (ZIN); $8 \mathrm{O}^{7} \mathrm{O}^{7}, 5$ 우, India: Rajasthan state, Chambal R., $25.85^{\circ} \mathrm{N} 76.56^{\circ} \mathrm{E}, 26 . I I .2011$, N.Vikhrev; $10^{7}$, 2 우, Israel: Yeruham $\left(30.99^{\circ} \mathrm{N} 34.90^{\circ} \mathrm{E}\right), 22 . \mathrm{VII} .1962$, J.Kugler (Tel-Aviv University, Israel (TAUI); $3 \mathrm{O}^{7} \sigma^{7}, 2$ 우, Mash'abbesade $\left(31.01^{\circ} \mathrm{N} 34.78^{\circ} \mathrm{E}\right), 21$. VII.1986, A. Freidberg (TAUI); $1 \sigma^{7}$, Kinneret Lake env., $32.7^{\circ} \mathrm{N} 35.6^{\circ} \mathrm{E}, 27 . X I .2011$, N.Vikhrev; $1 \mathrm{O}^{\circ}, 1$ 웅. Morocco: Quarzazate prov., $29.85^{\circ} \mathrm{N} 5.61^{\circ} \mathrm{W}, 30 . \mathrm{III} .2011$, A. Gusakov; $13 \mathrm{O}^{7} \mathrm{O}^{7}, 4$ OP, Turkmenistan: Mary prov., Kushka env. $\left(35.3^{\circ} \mathrm{N}\right.$ $\left.62.3^{\circ} \mathrm{E}\right), 20 . V .1990$, A.Ozerov; 2 + 9 , Ahal prov., Tejen, 15.V.1969, A. Zhelochovtsev.

\section{Lispe elegantissima Stackelberg, 1937}

Fig. 10.

Lispe elegantissima Stackelberg, 1937: 131. Type locality: Turkmenia, Tashaus.

TYPE MATERIAL EXAMINED. Holotype or "Turkmenia, Tashaus" (presently Turkmenistan, Dashoguz, $41.9^{\circ} \mathrm{N} 59.9^{\circ} \mathrm{E}$ ), 1937, A. Stackelberg in Zoological Institute St.-Petersburg (ZIN). ADDITIONAL MATERIAL. $190^{7} 0^{7}, 34$ 우, Kazakhstan: Kyzylorda reg., pond near Syr Darya R., $45.757^{\circ} \mathrm{N} 62.312^{\circ} \mathrm{E}, 15$ 19.V.2011, K.Tomkovich; $20^{7} \sigma^{7}, 2$ +o+, Tajikistan: «íeçîauüy Âàõøà» (the lower reaches of Vakhsh R.) = Khatlon prov., approx. $37.5^{\circ} \mathrm{N}$ $68.5^{\circ} \mathrm{E}$, 17.III.1944, A.Stackelberg (ZIN); $10^{\text {7 }}, 9$ 오, Turkmenistan Lebap prov., Chardzhou env., 25.IV.1990, A.Ozerov; 1 +, Ahal prov., Ashgabat env., 5.V.1990, A.Ozerov.

\section{Lispe nubilipennis Loew, 1873}

Fig. 11.

Lispe nubilipennis Loew, 1873: 244. Type locality: Sarepta (Russia, Volgograd env., $48.52^{\circ} \mathrm{N} 44.51^{\circ} \mathrm{E}$ ).

MATERIAL EXAMINED: 1 , Russia: Astrakhan reg., Baskunchak L. env., fresh pond, $48.165^{\circ} \mathrm{N} 46.82^{\circ} \mathrm{E}, 3-6 . V .2010$, K. Tomkovich.

DISCUSSION. Hennig's [1960: 416] guidelines on separation of $L$. scalaris and $L$. persica may be summarized as follows:

- Pedicel entirely yellow. Tibiae yellow. Scutum densely dusted, only laterally partly shining. Tergites 3 and 4 with brown spots, spots on tergite 3 small.

..persica Becker

- Pedicel only apically yellow. Tibiae darker. Scutum black, shining, dusted only on median part. Tergites 3 and 4 with large black spots scalaris Loew

I regard L. persica as a synonym of $L$. scalaris for the following reasons: the characters thought to be diagnostic vary gradually without clear border between the species (1); the key characters are often different among specimens collected on the same date and at the same locality and there is not strict correlation between the characters (2); the male genitalia were found identical (3).

In my opinion the most likely explanation of the variability is the difference between freshly emerged and aged specimens: the dusting on thorax and abdomen becomes more worn-out in aged ones, so that spring specimens (Morocco, India and Turkmenistan) are densely dusted, whereas those collected in summer or autumn (Israel) are darker and more shining.

The Lispe scalaris species-group also included two less studied species: L. elegantissima Stackelberg known from Central Asia and L. nubilipennis Loew, so far known from 2 female specimens collected in lower reaches of the Volga River.

The female holotype of L. nubilipennis was examined by Hennig [1960] who gave the following differences: dark pattern on wing indistinct, visible only at an acute angle of view but otherwise similar to that of L. elegantissima (1); abdomen laterally with separated black shining spots, not with uninterrupted black shining stripes as in L. elegantissima (2); anepisternum without black shining stripe which is present in $L$. elegantissima (3). The female specimen of L. nubilipennis I have fits Hennig's separation characters, but more material is necessary to clarify the situation.

ECOLOGY. According to my observations L. scalaris was found on the clay loam at banks of rivers, freshwater lakes or ponds, where it prefers sites rather remote from water where the clay is dried and forms a crust (= takyr/takir soil). All specimens of L. elegantissima and L. nubilipennis were collected in spring season near fresh water.

\section{Correction}

I have to apologize for an unfortunate mistake in my previous paper on Lispe taxonomy [Vikhrev, 2011a, Fig. 2.]: sternite 5 of Lispe draperi Séguy, 1933 was attributed to L. tentaculata (De Geer, 1776) and vice versa. The correct illustration is given below (Fig. 12).

ACKNOWLEDGEMENTS. Taxonomy of $L$. angustipalpis was clarified due to the kind help of Dutch colleagues Ben Brugge and Joke van Erkelens. I thank Oleg Kosterin (Novosibirsk) who suggested several useful corrections. I thank Adrian Pont (Oxford), Andrey Ozerov (Moscow) and Dmitry Gavryushin (Moscow) for their help.

\section{References}

Hennig W. 1955-1964. Family Muscidae // Lindner E. (Hrsg.) Die Fliegen der Palaarktischen Region. Stuttgart: Schweizerbart. Lfg.63b. $1110 \mathrm{~S}$.

Pont A.C. 1970. The type-material of Oriental and Australasian Muscidae (Diptera) in the Zoological Museum, Amsterdam // Beaufortia. Vol.18. No.231. P.77-111.

Snyder F.M. 1965. Diptera: Muscidae // Insects Micronesia. Vol.13. P.191-327. 

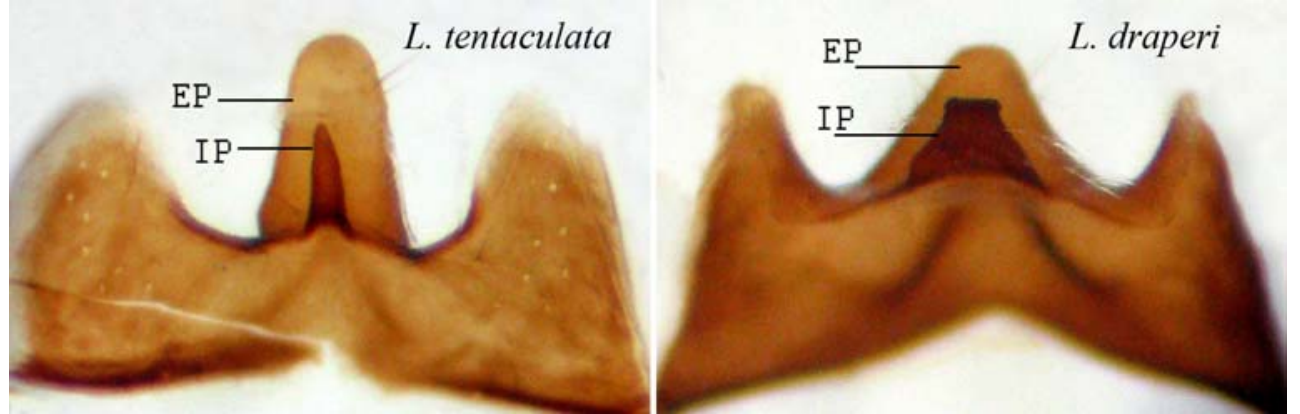

Fig. 12. Correct illustration to Vikhrev, 2011a, Fig. 2.

Рис. 12. Правильная иллюстрация к статье Vikhrev, 2011a, Fig. 2.

Stein P. 1920. Fauna Simalurensis, Anthomyidae. Einige Anthomyiden von der Insel Simalur bei Sumatra // Tijdschr. Entomol. Bd.62(Suppl.). S.40-46.

Vikhrev N. 2011a. Review of the Palaearctic members of the Lispe tentaculata species-group (Diptera, Muscidae): revised key, synonymy and notes on ecology // ZooKeys. Vol.84. P.59-70.

Vikhrev N. 2011b. Taxonomic notes on the Lispe leucospila species-group (Diptera, Muscidae) // Russian Entomological Journal. Vol.20. No.2. P.215-218. 